\title{
Da gravidez de "risco" às "maternidades de risco”. Biopolítica e regulações sanitárias nas experiências de mulheres de camadas populares de Recife
}

\section{| ${ }^{1}$ Alfonsina Faya Robles |}

Resumo: A categoria epidemiológica do risco organiza atualmente, no Brasil, a gestão das gravidezes com o objetivo de atingir metas de saúde, como a redução das mortalidades infantil e materna. Tal categoria vem enquadrada em toda uma transformação no sistema de saúde, de passagem para uma nova etapa biomédica baseada na avaliação e na vigilância de riscos. Poucos trabalhos na área das ciências sociais tomaram o risco como objeto de estudo empírico a partir de uma perspectiva de análise crítica das mudanças que ele introduziu nas práticas sociais. Baseado num trabalho de pesquisa mais amplo, com metodologia etnográfica, o artigo propōe-se a examinar esta categoria na gestão das gravidezes nos serviços públicos de saúde e em mulheres de camadas populares na cidade de Recife. $\mathrm{O}$ artigo analisará as modalidades de regulação, cada vez mais individualizantes e sanitarizadas, ligadas à utilização da noção de risco pelos profissionais da saúde e às representaçôes sociais estigmatizantes para as mulheres de camadas populares. Finalmente, o artigo relativiza a força disciplinadora dessa categoria biomédica para mostrar como ela é subjetivada, pelas mulheres, em uma experiência relacional da gravidez.

> Palavras-chave: risco; gravidez; regulação; medicalização; sanitização.
1 Bolsista CNPq, Programa de Pós-Graduação em Saúde Coletiva, Instituto de Medicina Social, Universidade do Estado do Rio de Janeiro. Rio de Janeiro-RJ, Brasil. Endereço eletrônico: afaya@univ-tlse2.fr
Recebido em: 10/03/2014 Aprovado em: 02/12/2014 


\section{Introduzindo a questão do risco na área de saúde materno-infantil no Brasil}

A expansão da categoria "risco" verifica-se tanto no campo da medicina clínica, como em toda a saúde pública brasileira, envolvendo a atenção básica. No âmbito da saúde, a noção se insere num processo mais amplo, de transição entre uma medicina clínica ligada ao passado do paciente (anamnese) a outra fundamentada na previsão de futuras patologias (probabilidades). Percebe-se uma mudança importante na perspectiva temporal, relativa aos métodos e práticas de trabalho na área da saúde.

O risco enquanto categoria objetiva carrega significaçôes socioculturais que modificam seu significado e definem uma "epidemiologia do risco" (BERLIVET, 2001). Forjado nos anos 1950, em torno da investigação etiológica de doenças degenerativas, desde 1980, esse paradigma tem se estendido ao estudo de doenças transmissíveis, "ampliando ainda mais o alcance do campo de análise estatística em saúde” (BERLIVET, 2001, p. 101). A principal questão da saúde pública torna-se a prevenção, que age sobre os "fatores de risco, estatística e epidemiologicamente estabelecidos" (DOZON; FASSIN, 2001, p. 23), e faz parte de uma mudança biopolítica na regulação sanitária de comportamentos.

No Brasil contemporâneo, a categoria sanitária "risco" tem se expandido, como modalidade de pensamento e como categoria operatória acerca da gestão da vida e da saúde (NEVES, 2008). O risco opera em dois níveis biopolíticos: vigilância epidemiológica das populações e nível micro de prescrição de comportamentos individuais. $\mathrm{O}$ foco são menos as doenças e as deficiências que a saúde como tema de autotransformação moral (CLARKE et al. 2000).

O risco surge assim como categoria reguladora na saúde maternoinfantil e da gravidez de mulheres de camadas populares, usuárias do SUS (Sistema Único de Saúde). Desse modo, as técnicas de regulação dos corpos e comportamentos mudam, no âmbito da saúde básica. Em algumas gestações, a atribuição do risco se traduz por um status, conferido à mulher, enquanto "mãe de risco": espera-se dela uma série de comportamentos ligados a determinado papel materno. Essa assignaçãa ${ }^{I}$ do risco ocorre de distintas maneiras, segundo o contexto social, modulada por características como a de ser usuária da rede pública ou do setor privado de saúde, e a de pertencer a segmentos populares, médios ou altos da sociedade. 
As classificações de gestações a partir da categoria risco têm a finalidade de controlar os efeitos de morbimortalidade futura. Contudo, há dificuldades na classificação e efeitos da assignação na maneira como as mulheres vivem hoje a gravidez. Na gestão de gravidezes, a utilização do risco estabelece diferenças tanto entre as gestações quanto sobre o tipo necessário de técnica de regulação. Distinguimos dois tipos de técnicas. O primeiro reúne as chamadas medicalizadas de intervenção. O segundo, as que seguiram um processo de sanitarização e recaem sobre mulheres que engravidaram na juventude, "por acidente", consideradas mães “indignas" ou "incapazes". O escopo principal do artigo é analisar a regulação dessas gestações e procura-se evidenciar os significados do risco a partir de definições mais sanitarizadas que medicalizadas. ${ }^{2}$

Trata-se de mostrar como classificações vinculadas a valores culturais são substituídas pelas classificações biomédicas. Valores e referências de determinados profissionais e serviços públicos de saúde se aplicam, assim, a uma série de mulheres consideradas "não aptas" ao papel materno. As técnicas de regulação permitem a construção de um papel materno e de um "projeto de criança" (BOLTANSKI, 2004) individual e sanitarizado.

$\mathrm{O}$ artigo estrutura-se sobre a reconstrução do contexto de pesquisas que levaram à problematização do risco gestacional e ao fornecimento de dados empíricos para o presente estudo. Logo busca-se verificar como se construiu a definição institucional do risco na gravidez e seus marcadores, os "fatores de risco", no Brasil. O artigo expõe como o risco se situa entre dois registros distintos de medicalização e de sanitarização da experiência de gravidez e apresenta as dificuldades em utilizar essa categoria no tratamento de gestações, devido às dificuldades de avaliação dos "fatores". Isso leva a umas práxis que desliza gradualmente do campo médico para o campo moral e cultural, no qual a categoria risco legitima intervenções em outras esferas da vida de mulheres de camadas populares. Por fim, serão examinadas mais "de perto" (MAGNANI, 2002) experiências de risco gestacional através do discurso de mulheres, destacando-se outros significados para a categoria, assim como uma subjetivação do risco, que passa por sua inclusão numa rede social e resulta numa gestão relacional da gravidez. 


\section{O contexto de duas pesquisas sobre maternidade e mortalidade infantil em Recife}

As questôes levantadas no presente artigo vêm principalmente de pesquisa desenvolvida em tese de doutorado de Sociologia, na qual foram tratadas experiências de maternidade em camadas populares do Recife. Também foram mobilizados dados e reflexôes abordados por pesquisa coletiva sobre a mortalidade infantil nessa mesma cidade, da qual a autora participou. ${ }^{3}$

A tese doutorado questionou a maternidade e a relação de filiação, a partir de especificidades de famílias de camadas populares pontuadas por vários autores (FONSECA, 1995, 2004, 2005; WOORTMANN, 1987; SARTI,1996; DIAS; DUARTE; CAMPO-GOMES, 2008, entre outros): as desigualdades de gênero, no que diz respeito às responsabilidades parentais; a predominância de um modelo de intercâmbios familiares, de tipo matrilateral; e o fenômeno de circulação de crianças entre famílias (FONSECA, 1995). Portanto, a tese analisou a construção da experiência materna, em um contexto de certa dissociação entre o laço biológico e o laço cotidiano de parentesco (WEBER, 2005), experiência inserida em padrões sociais que vão além da unidade doméstica e da "família nuclear".

Contudo, o trabalho de campo etnográfico questionou a intensa participação do sistema de saúde pública no Brasil - que chamamos de "dispositivo de regulação" - na conformação das experiências mais íntimas das mulheres encontradas em Recife. Durante o estudo, notou-se o empenho dos serviços em intervir nas práticas maternas das mulheres, produzindo mudanças inéditas na área de saúde materno-infantil e reprodutiva.

A pesquisa etnográfica durou 14 meses, em 2005-2006 e 2008, com enfoque de tipo qualitativo, através dois instrumentos metodológicos: observaçôes sistemáticas e entrevistas semiestruturadas ${ }^{4}$ (no total de 40 entrevistas com mulheres e profissionais de saúde). O campo foi dividido em dois espaços diferentes. $\mathrm{O}$ espaço institucional de três maternidades públicas localizadas em distintos pontos da cidade, com níveis diferentes de complexidade (duas tinham serviço pré-natal de alto risco). Ali foram coletados dados a partir do cotidiano dos serviços, dos fluxos e das interaçooes entre profissionais e usuárias. Um bairro da periferia de Recife e sua Unidade de Saúde da Família. Nessa área foram acompanhadas as práticas dos profissionais e a experiência de 12 
mulheres, ao longo de vários encontros, em seus domicílios, na unidade ou em espaços de sociabilidade.

Nesse mesmo bairro, a pesquisa coletiva sobre mortalidade infantil acompanhou casos de óbitos infantis. Procurou-se analisar representações sobre o risco ligado à mortalidade neonatal e infantil em mães adolescentes e adultas, e foram realizadas entrevistas em profundidade com mães, pais e pessoas da rede, assim como com gestores e profissionais de saúde.

\section{Zoom no dispositivo de regulação}

Desde 1990, grandes mudanças demográficas e epidemiológicas afetaram a saúde reprodutiva das mulheres (baixa taxa de natalidade, aumento do uso de meios de contracepção "modernos", redução da mortalidade infantil, etc.) e elas estão intimamente relacionadas com a expansão do sistema público de saúde (VÍCTORA et al., 2011). As estratégias implementadas e os programas verticais de saúde pública estão direcionados para populações com baixos indicadores, como é o caso nas regiōes mais pobres, como o Nordeste.

Porém, o desenvolvimento do sistema de saúde pública no Brasil tem privilegiado uma perspectiva da saúde materno-infantil em detrimento de uma perspectiva da saúde reprodutiva da mulher, propugnada pelos movimentos de mulheres. $\mathrm{O}$ modelo de assistência na saúde básica se "afastou de uma perspectiva gênero" (tendo como referência a conformação do PAISM) para "aproximar-se da família” (SCOTT, 2005, p. 77). A prioridade na queda da mortalidade infantil, com redução exclusiva da saúde da mulher à sua esfera materna, se conjuga ao modelo de assistência pública, utilizado majoritariamente por camadas pobres do país. O Estado brasileiro encontra nas mulheres de camadas populares o "alvo" e as "aliadas" na obtenção de resultados sanitários. Como Parry Scott diz: "As mães são as cúmplices dos profissionais de saúde, pois somente por intermédio delas é que se pode alcançar a meta de reduzir a mortalidade infantil, meta prioritária e principal indicador de sucesso da equipe de saúde" (SCOTT, 2005, p. 86).

Um elemento fundamental desse dispositivo tem sido a implantação, promoção e sistematização do atendimento no pré-natal, a partir de ações programáticas, protocolos e políticas nos distintos níveis administrativo-territoriais. Em 2010, $60 \%$ das parturientes tinham realizado sete ou mais consultas de pré-natal, conforme recomenda a Organização Mundial da Saúde. Na Região Nordeste, 
embora a proporção fosse menor (45\%), chegou a aumentar consideravelmente na última década (em 2000, a proporção de mulheres tendo realizado sete ou mais consultas de pré-natal era de apenas $32 \%$ ). Da mesma maneira, a proporção de gestantes aumentou, com início do acompanhamento ainda no $1^{\circ}$ trimestre de gestação, entre 1996 e 2006 (de 66\% para 84,1\%).5 A eficiência em garantir a consulta precoce no período pré-natal deve ser interpretada à luz do trabalho minucioso de vigilância nos bairros - efetuado pelos ACS e enfermeiros para a rápida assignação das mulheres grávidas (FAYA-ROBLES, 2012). Esse aumento da frequência de consultas pré-natais é fundamental para compreender a importância da noção de risco nas experiências de gravidez. Desde a primeira consulta, o preenchimento do "cartão da gestante" vai determinar os graus de risco da gestação. Como lembram Corrêa e Guilam (2006, p. 42):

[...] por meio do discurso biomédico, a mulher grávida se vê cercada, hoje, de uma rede de vigilância de seu corpo, passando a ser responsabilizada não só pela própria saúde, mas também pela produção de um feto saudável. Por tudo isso, o pré-natal é um lócus privilegiado do discurso de risco.

No entanto, e como as autoras supracitadas vislumbram, paralelamente às políticas públicas da saúde materno-infantil que participam de um processo de medicalização da gravidez e do parto, desenvolve-se uma série de políticas que vão no sentido de "humanização" e desmedicalização. Esses dois processos estão em diálogo constante. Enquanto as mulheres que dão à luz em clínicas particulares são as que experimentam as mais altas taxas de cesárea (VÍCTORA et al., 2011), as mulheres que dão à luz nos serviços públicos têm acesso limitado a tais práticas e são alvo de políticas de humanização (FAYA ROBLES, 2008; DENYER, 2009). A humanização, que pode ser incluída em um processo amplo de sanitarização, tem se expandido fortemente nos serviços públicos e refere-se, portanto, às mulheres de camadas populares. Se o modelo de gravidez e de parto humanizado é uma reivindicação de mulheres das camadas médias, construído na margem das instituições hospitalares e públicas, encontra hoje no Brasil forte expansão nos serviços públicos. As políticas públicas de humanização são muito heterogêneas, mas têm em comum uma abordagem do parto e do nascimento como "processos naturais" (TORNQUIST, 2004), assim como a valorização dos modos de intervenção mais "soft" e "flexíveis".

Juntamente ao processo de medicalização da saúde reprodutiva, forjou-se outro processo, mais silencioso, porém eficaz, provocado pela introdução de 
várias práticas e técnicas, das quais o movimento da humanização é apenas uma das demonstraçôes. Há, portanto, processos bastante originais que introduzem novas técnicas de controle e categorizaçôes das pessoas, que suavizam a imagem dos serviços públicos de saúde, marcados pela despersonalização e padronização (SANABRIA, 2010) através da medicalização.

O processo de sanitarização poderia ser equivalente ao de "healthization" (CONRAD, 2007), que se refere à onipresença e à supremacia da "saúde", no sentido mais amplo, e segundo "definição positiva" (CAMARGO, 2013), não como a ausência de doenças ou complicações, mas encarando a saúde como uma "realização em si e como uma autorrealização" (CLARKE et al., 2000 p. 26).

Devido às aporias nas perspectivas teóricas ligadas à questão da medicalizaçãosanitarização, propõe-se uma abordagem focalizada nas realidades empíricas observadas e, ao nosso ver, mais dialógica, onde não se trata de processos históricos e sociais, mas de registros que podem rivalizar ou se articular. Na sequência do trabalho de Hislop e Arber (2003), seguimos a distinção realizada pelas autoras entre os "registros" de medicalização e de sanitarização, para observar, a partir da categoria "risco", como se constroem as interações, negociações e conflitos entre os dois conceitos. Sucintamente definida pelas autoras, a medicalização refere-se à maneira de compreender os fenômenos, a partir do registo da doença, da patologia e da tecnologia. Pelo contrário, o registro da sanitarização mobiliza a dimensão psíquica e de bem-estar mental com o intuito de explicar situaçōes e fenômenos fisiológicos. ${ }^{6}$ Nesse sentido, segundo a tipologia elaborada por Hislop e Arber (2003), em algumas gravidezes de mulheres de camadas populares, pode-se especular sobre o fato de a aplicação da categoria "risco" incluir o registro da sanitarização.

No contexto recifense, é durante as consultas pré-natais que o dispositivo procura não somente uma regulação dos corpos gravídicos, mas também a construção de um "projeto de criança" (BOLTANSKI, 2004), responsabilizando individualmente as mulheres e procurando levá-las a "assumir" a gestação e os riscos por ela acarretados. Em nosso universo de estudo, a particularidade da individualização pelo risco decorre do fato de a grande maioria das mulheres encontradas vivenciarem gravidezes "não previstas" (BAJOS; FERRAND, 2002), necessitando "assumi-las" para a construção de um projeto de criança em consonância com a visão do dispositivo. Esse objetivo de uma "gravidez assumida” compara-se aos propósitos de certas organizaçôes sociais, descritos por 
Duarte et al. (1992), de "conversão" de pessoas de camadas populares para a "racionalização", a "individualização" e a "responsabilização" das relações com seus corpos.

Porém, algumas nuances aparecem em novas formas de regulação e de "conversão" das mães de camadas populares. Menos do que pela imposição de roteiros de comportamentos e cuidados, a partir de relações hierárquicas, entre o profissional e o leigo, o processo de "conversão" se faz integrando discursos sobre o bem-estar gravídico, a singularidade de cada mulher e a consideração de suas perturbações emocionais e psíquicas. Assim, a conversão da mulher passa menos pelo registro do "dever" que pelo da "realização" de si mesma. O projeto de criança deve apresentar-se como uma "realização biológica" que seja ao mesmo tempo um projeto de saúde "contínuo [...], uma realização em si, mas também uma realização de si mesmo" (CLARKE et al., 2000, p.26). Cria-se então uma fusão sanitarizada entre o cuidado de si da mulher e o cuidado do outro, a criança: escopo importante para a saúde pública. A partir da noção de risco, a organização dos cuidados no pré-natal busca atingir o objetivo de concretização de um projeto sanitarizado e individualizado de criança.

\section{O risco e as vicissitudes na avaliação}

Desde inícios dos anos 1970, a literatura médica e epidemiológica compreende artigos sobre "risco gravídico", ligados sempre à mulher e procurando medições adaptadas para o estabelecimento de pautas de avaliação. ${ }^{7}$ Essa literatura incentiva profundamente a intervenção nos períodos de pré-natal, parto e puerpério a partir da noção de risco, procurando tanto o estabelecimento de programas de saúde materna, quanto ressaltando a implicância da mãe no processo. Há, assim, uma reviravolta na participação do paciente nos processos fisiológicos e de saúde-doença, em paralelo à noção de risco. A frase inicial de um desses artigos precursores é ilustrativa: "é preciso que mulheres em idade fértil adotem medidas que permitam evitar ou controlar os riscos inerentes à gestação" (CANDEIAS, 1980, p. 320).

Se em 1983 aparece o primeiro Manual sobre enfoque de risco na saúde materno infantil, publicado pela Divisão Nacional de Saúde Materno-Infantil do Ministério da Saúde, em parceria com a OMS e a OPS, é somente no final do século XX que se consolida o atendimento pré-natal, abrindo a possibilidade de 
sistematização da avaliação do risco. Em 2000, o Ministério da Saúde publicou o primeiro Manual (SILVEIRA, 2000) para a gestão de gravidezes de "alto risco", destinado a profissionais e gestores de saúde pública, o qual define o risco nos seguintes termos:

[...] a gestação é um fenômeno fisiológico e, por isso mesmo, sua evolução se dá na maior parte dos casos sem intercorrências. Apesar desse fato, há uma parcela pequena de gestantes que, por serem portadoras de alguma doença, sofrerem algum agravo ou desenvolverem problemas, apresentam maiores probabilidades de evolução desfavorável, tanto para o feto como para a mãe. Essa parcela constitui o grupo chamado de "gestantes de alto risco" (BRASIL, 2010, p. 11).

A epidemiologia distingue então, dentro de uma população, um grupo de risco, pela soma de indivíduos que apresentam determinadas características e que são probabilidades de adoecer ou de morrer, mudando a visão dos processos de saúde-doença. Dentro dessas características, há fatores que serão ligados às condições sociais e comportamentos das pessoas.

Notam-se as dificuldades para avaliar o risco quando esta noção se associa com probabilidades, assim como a correlação direta entre "fatores de risco" e complicações que nem sempre podem ser explicadas a posteriori por aqueles mesmos fatores. Assim, não se parte de uma situação observável na experiência, mas de uma situação que é deduzida (CASTEL, 2011). Em outras palavras, há uma passagem rápida entre a associação estatística e a relação causal - passagem que pode esconder preconceitos, valores e crenças que conduzem ao estabelecimento dessas causalidades. Na prática, os médicos e outros profissionais de saúde muitas vezes não dispõem dos parâmetros e nem das ferramentas materiais necessárias para controlar a tomada de decisões, o que os leva a serem guiados por seus próprios valores sobre a maneira como a gravidez deve ser vivenciada.

Em Recife, designar uma gravidez como sendo de "alto risco" é uma tarefa efetuada geralmente pelos profissionais de saúde de proximidade (enfermeiro/a ou médico/a encarregados do pré-natal nas unidades básicas, ou agentes comunitários). Assim, uma das competências dos enfermeiros, além de "educar e orientar" os ACS sobre "os sinais de risco", é a de "avaliar riscos biológicos e psicossociais e programar a assistência conforme os níveis de risco" (BRASIL, 2011, p. 37).

Para o diagnóstico desses níveis de risco, o Ministério da Saúde estabeleceu uma lista de "fatores de risco" a serem considerados. No momento do trabalho 
de campo, as equipes ainda utilizavam a lista de fatores de $2000,{ }^{8}$ agrupados em quatro categorias.

O primeiro grupo é o das "características individuais e condições sociodemográficas desfavoráveis", compreendendo a idade (menor de 199 e maior de 35 anos); a ocupação da mulher (esforço físico excessivo, exposição a agentes tóxicos físicos ou químicos, carga horária extensa, rotatividade de horário, estresse); uma situação familiar "insegura" e a "não aceitação" da gravidez; uma situação conjugal "insegura" (instável); a baixa escolaridade (menos de 5 anos de estudo regular); condições ambientais desfavoráveis; a dependência de drogas lícitas ou ilícitas; altura menor do que $1,45 \mathrm{~m}$, peso menor do que $45 \mathrm{~kg}$ ou maior do que $75 \mathrm{~kg} .{ }^{10}$

O segundo grupo de "fatores de risco" contempla aqueles relacionados à "história reprodutiva anterior": abortos habituais; mortes perinatais explicadas ou sem explicação; partos pré-termo; esterilidade-infertilidade; intervalos internatais inferior a dois anos ou superior a cinco anos; diabetes gestacional; a nuliparidade ou a multiparidade; etc.

O terceiro grupo de risco está ligado às "condições clínicas preexistentes": hipertensão arterial; cardiopatias; pneumopatias; endocrinopatias (diabetes e tireoidopatias); epilepsia; hemopatias; doenças infecciosas ou autoimunes; etc.

Por fim, o quarto grupo abrange complicações obstétricas que aparecem no decorrer da gravidez: uma exposição acidental a fatores teratogênicos; um desvio no crescimento normal do útero; uma alteração no volume do líquido amniótico ou no número de fetos; um trabalho de parto prematuro ou gravidez prolongada; ganho ponderal inadequado; pré-eclâmpsia ou eclampsia; hemorragia; diabetes gestacional; etc.

A avaliação de uma gestação de "alto risco" a partir desses "fatores de risco” parece problemática para os próprios profissionais de saúde que fazem a triagem. Apesar de listarem os "fatores de risco" associados a uma gravidez, os protocolos não se referem à quantidade necessária deles para que a gravidez seja considerada de alto risco. De igual forma, não há indicações para saber se cada um desses fatores tem a mesma ponderação para a classificação dos casos. Como detectar cada um desses fatores de risco no decorrer de consultas ginecológicas que geralmente são curtas e desprovidas de material e tecnologia para sua avaliação? O "alto risco" se forma pela soma desses fatores 
ou por determinadas combinações? É nessa lacuna nas próprias definições

institucionais e nas dificuldades da avaliação na prática, que outros tipos de classificaçōes e de visōes do risco gravídico se conformam.

Algumas características, sobretudo aquelas do primeiro grupo de fatores, as "características individuais e condições sociodemográficas desfavoráveis", poderiam formar em si mesmo um "grupo de risco", cuja homologia com a população de estudo é sugestiva: são mulheres que entram cedo no ciclo materno, de baixa renda, que vivem em "ambientes difíceis" e em configurações familiares que podem ser, na visão dos profissionais, "inseguras", pois não se enquadram no modelo nuclear de família. Essas mulheres podem apresentar quadros de "não aceitação da gravidez", uma vez que geralmente essas gestações são "não previstas" (BAJOS; FERRAND, 2002). Neste sentido, é importante observar com Marcel Calvez (2001): uma abordagem da doença a partir da categoria risco tende a moralizar o perigo ligando-o à construção de uma comunidade. Com relação ao risco gravídico, aparecem claramente os contornos de uma "comunidade" de mães pobres que seguem padrões reprodutivos "outros" e, portanto, se convertem em possíveis "mães de risco".

Segundo os manuais, mesmo ao considerar apenas o primeiro grupo de "fatores de risco" (renda, instabilidade conjugal, ambiente desfavorável, etc.), ocorreria uma superlotação nos serviços de "alto risco", em detrimento das consultas pré-natais realizadas no posto de saúde, contrapondo-se aos propósitos das políticas de prevenção: absorver a maior quantidade de casos no nível básico de atenção. Eis aqui outro paradoxo entre as perspectivas da prevenção e a abordagem de risco: a despistagem sistemática e exaustiva (CASTEL, 2011) deve ser acompanhada de uma ação delimitada e econômica sobre uma população reconstituída abstratamente pela combinatória de fatores de risco. Como explicam Jean-Pierre Dozon e Didier Fassin (2001, p. 8): “a identificação de um fator de risco não procede simplesmente de uma tradução da realidade em dados estadísticos, ela envolve também os pressupostos através dos quais o mundo social é decodificado e interpretado".

Além das classificações realizadas a partir de dados biomédicos (agravos e doenças físicos e clínicos) se produz outra classificação das gestações a partir de dimensôes sociais e individuais das mulheres, que serão alvo de intervençôes sanitarizadas cujo objetivo é regular já não tanto o corpo como a relação de filiação. 

do biológico ao social

$\mathrm{Na}$ última edição do Manual de atendimento a gestaçôes de risco (BRASIL, 2010), é dada ênfase aos riscos "reais" e clínicos, deixando os riscos ligados às condiçōes sociais em segundo plano. Isso é recente e pode estar ligado a reavaliaçôes da perspectiva de risco no campo materno-infantil. Porém, na prática, há sempre um deslocamento entre a "avaliação" - supostamente fundada em evidências e fatos científicos - e a "gestão" do risco - que resulta de decisões quotidianas das equipes, assim como de decisões administrativas e políticas. Esse deslocamento marca um vão perpassado pelas crenças, valores e representações com as populaçōes que devem ser administradas.

Se para algumas patologias ou fatores de risco do primeiro grupo, os profissionais de saúde entendem que o risco é contestável, minimizando os perigos e limitando o acompanhamento ao nível local (escolaridade baixa da mãe, condições de trabalho ou ambientais desfavoráveis, etc.), outros fatores estão associados automaticamente a uma "gravidez de alto risco". Durante a pesquisa de campo em Recife, esse era o caso das mães "adolescentes". Assim, quando se questiona sobre o modo de identificação de casos de gravidez de "alto risco", a "gravidez na adolescência" surge espontaneamente nas respostas das agentes comunitárias de saúde. O risco parece então conjugar-se com outros fatores como as relações conjugais "instáveis" e a "não aceitação" da gravidez:

A maioria das adolescentes de hoje [...] elas escondem, dependendo do parceiro elas escondem o máximo que pode, quando vem dizer (aos serviços) já tá quase impossível de esconder a barriga.

O debate público sobre a gravidez na adolescência e a abordagem a partir do risco (BRANDÃO, 2006) têm contribuído na construção de um "problema social” (HEILBORN, 2006, p. 32). A figura da jovem gravida é construída pela superposição de imagens negativas: um corpo que não é adequado para a reprodução, a imaturidade psicológica, as más condições sociais estabelecidas como causas e/ou consequências da gravidez (HEILBORN, 2006). Nestas gestações, o risco biomédico, o risco social e o psicológico parecem convergir.

No entanto, vários estudos questionam a construção de um perfil de gravidez de alto risco que se aplique a todas essas mulheres. $\mathrm{O}$ risco biomédico seria aplicável apenas a parte do grupo: aquelas com imaturidade ginecológica 
(mulheres com menos de 15 anos ou que tiveram a menarca menos de dois anos antes da gravidez) (STERN; GARCIA, 1999). Estudo realizado em Porto Alegre (BUCHABQUI et al., 2006) mostra que de 821 encaminhamentos para uma unidade pré-natal de “alto risco”, 24,5\% eram incorretos e não necessários. Entre as mulheres mais jovens (menos de 20 anos), essas transferências inadequadas para serviços especializados foram de 34,7\%. Trata-se, segundo os autores, de decisões administrativas nas quais o único parâmetro fora a idade da mulher. Sem desconsiderar que a maioria dos casos precisavam de encaminhamento para serviços de "alto risco", como demostram os dados citados anteriormente, percebe-se numa parcela deles a primazia de uma lógica administrativa na atribuição do risco.

A inclusão de mulheres mais jovens na categoria de gestações de risco está radicada no pressuposto da saúde pública que estabelece uma relação causal entre "gravidez na adolescência" e "mortalidade infantil" (KATZ, 1999; COSTAMARTINS; HEILBORN, 2006). Sendo este último um imperativo dos órgãos sanitários no Nordeste, podemos inferir o encaminhamento maciço de mulheres jovens para serviços de alto risco.

No entanto, reunir sob o nome de "gravidez na adolescência" todas as gestaçôes de mulheres jovens (com base na definição da maioridade civil de 18 anos) produz dois efeitos contrários. O primeiro é a invisibilização dos riscos "reais" e os altos percentuais de problemas nas gestações em faixas mais jovens desse grupo (menores de 15 anos); por outro, se estabelece um controle excessivo nas jovens com maior idade. Paradoxalmente, a consequência da homogeneização e da objetivação pela formação do grupo que será vigiado é a imprevisão dos riscos fisiológicos. Assim, se se divide o grupo em duas faixas etárias, encontramos taxas de mortalidade infantil muito díspares. Em 2006, para meninas de 10 a 14 anos, a taxa de mortalidade neonatal chegou a $40 \%$, enquanto entre as jovens de 15 a 19 anos ela foi de apenas 8,5\%, taxa menor do que a observada em mulheres com mais de 20 anos (10,24\%). ${ }^{11}$ Desse modo, o discurso sobre o risco se aplica desnecessariamente a um grupo que a priori não apresenta riscos biológicos, respondendo a outras exigências, menos médicas e mais culturais.

No entanto, obscurecem-se os riscos em mulheres mais velhas (tanto os fatores sociodemográficos, quanto os clínicos ou fisiológicos) além daqueles relacionados ao genitor, provocando disparidades de tratamento baseadas na idade e no sexo. Riscos 
relacionados ao "pai" são ofuscados pela formulação da unidade mãe-filho como unidade fundamental do cuidado sanitário. Destarte, nas primeiras consultas do pré-natal, e com o objetivo de preencher o "cartão de gestante", são feitas perguntas relativas à existência de possíveis doenças hereditárias da família materna. Jamais são questionados possíveis antecedentes da família paterna, reforçando a distância dos homens jovens com os serviços de saúde (SCOTT, 2007, p. 4).

A minoridade como "fator de risco" traz questionamentos para os próprios profissionais, os quais devem enfatizar e se referir aos "casos extremos" de uma "criança nascendo de outra criança". Essa hipérbole justifica a intervenção. Assim, uma funcionária do distrito sanitário responde à pergunta de como eles organizam a noção de risco:

Eu sei que em alguns casos, por exemplo, a faixa etária da mãe, às vezes, ou a diabete, da hipertensão, eu sei que esses são os indicativos para encaminhar para o alto risco, para a unidade de alto risco. Agora no caso das adolescentes... Quais são os critérios que utiliza-se? É só a idade, porque tem muitas adolescentes que, apesar da idade, têm uma saúde boa que você pode fazer um pré-natal no PSF. [...] Mas apesar do que a gente sabe que é a questão da gravidez na adolescência não é uma coisa simples, o corpo da mulher, a gente vê uma criança com 10 anos grávida [...]. Pra mim isso pode acarretar vários problemas pra ela e pode se tornar uma gravidez de alto risco, por que assim, uma criança que tá dando luz a outra criança [...] tanto não só a questão orgânica, mas também na cabeça dela, o que ela tem de entendimento com aquilo ali que tá passando, naquela transformação, ela acabou de menstruar e um dia desses já tá (grávida).

Alma e corpo se misturam e, mesmo em casos onde o registro do risco é evidentemente fisiológico (como no caso do corpo de uma criança de 10 anos) a justificação da intervenção inclui também o problema da "cabeça", "do entendimento", pois "a gravidez na adolescência” faz parte de um conjunto mais amplo de gestaçôes em mulheres encaradas como incapazes de ser mães ou mulheres desviantes em relação ao padrão reprodutivo veiculado pelo dispositivo de regulaçãa. A assignação do "risco" pode ser também um corretivo ao desvio e implica um excedente de controle sanitário.

Longe de ser uma categoria "desencarnada” (CALVEZ, 2001, p. 127), o risco é um recurso cultural através do qual a saúde pública procura impor padrōes desejáveis de conduta. Finalmente, se a noção de risco "é um vocábulo especialmente polissêmico e, portanto, dá margem a muitas ambiguidades" (CASTIEL, 1996, p. 240), ela é muito operativa justamente pelo seu caráter 
hipermóvel, podendo deslizar-se temporal e causalmente, legitimando a intervenção sobre vários planos.

\section{Uma noção escorregadia}

Oriscopode, por exemplo, sercolocadoantes doinício dagravidez, transformando a "gravidez" em um risco para a mulher. Nos discursos de profissionais, o risco torna-se "o risco de engravidar" e a gravidez em uma complicação a partir de "fatores de risco", deslocados então para os comportamentos e "estilos de vida”, com ênfase na sexualidade das jovens de camadas populares. O "risco de engravidar” está relacionado à classe social, já que nas camadas médias as jovens dificilmente têm gravidezes indesejadas (seus recursos financeiros e apoio familiar permitem realizar abortos seguros). Nesse sentido, a gravidez na adolescência se torna um "problema de saúde pública" que, objetivado pela noção de risco, alimenta discursos alarmistas sobre a sexualidade nas camadas populares. O discurso do risco seria mais uma etapa da institucionalização da gravidez adolescente como um problema (HEILBORN, 2006, p. 32-34), onde a "vida sexual e afetiva desregrada" (KNAUTH, 2012:548) dos jovens pobres é um fator de risco. Em uma reunião sobre gravidez na adolescência, organizada pelo posto de saúde, uma jovem médica disse:

Não é pela falta de acesso aos contraceptivos ou informaçôes, mas é devido à banalização da relação sexual. Sexo, já não é mais amor, não há privacidade, não há nenhuma ligação, é uma coisa animal.

Além de assimilar sexualidade a "fator de risco", o perfil de "mãe adolescente" institucionalizado dessa maneira raramente pode reproduzir o modelo idealizado da família nuclear de classe média. Uma ACS descreveu terrivelmente famílias formadas por "mães adolescentes":

As famílias estão totalmente [...] desestruturadas. Porque às vezes elas estão sem referência [...]. Alguns pais estão em presídios, outros são bêbados, outros abandonaram mesmo, as mães às vezes se prostituem para manter, enchem a casa de gente errada, que vêm, fumam maconha ou outros tipos de droga... então são famílias assim, que realmente estão sem futuro.

Aqui aparecem vários dos indicadores fornecidos pelo Ministério da Saúde para a detecção de uma gravidez de "alto risco": relação conjugal "insegura", uso de drogas ilícitas, ambiente desfavorável, etc. Em certo sentido, esses fatores não 
são mais um risco para a jovem (engravidar) ou para o processo gestacional, mas para a futura criança que vai crescer ali. A força da abordagem baseada no risco é a de projetar calamidades para o futuro da criança, a partir de condições adversas criadas hoje pela própria mãe.

Outro deslocamento temporal do risco gestacional se produz na revelação, por parte dos profissionais, da existência de um "risco relacional" entre mãe e feto, o qual deve ser detectado já no pré-natal. Esse risco relacional é destacado por vários profissionais de saúde e torna-se uma esfera particularmente importante da ação e da intervenção. No "cartão de gestante", algumas perguntas parecem sugerir os possíveis riscos já mencionados:

Dúvidas? Sim - não.

Gravidez planejada? Sim - não.

As respostas - positiva para a primeira pergunta e negativa para a segunda induzem a simplificar processos psíquicos e simbólicos pelos quais uma mulher grávida pode passar, as dúvidas que ela experimenta, e parecem supor, de maneira etnocêntrica, que somente uma "gravidez planejada" resulta em crianças "queridas".

Aqui, o "alto risco" da gravidez resulta num risco relacional da mulher com a criança e o controle medicalizado da gravidez torna-se regulação sanitarizada da maternidade. A importância desse "risco relacional", no contexto brasileiro, se revela quando consideramos que a esfera do risco se constrói nos limites da proibição do aborto. Esses "fatores de risco" relacionais se constroem tanto nas representações de profissionais como em instrumentos de medida do risco (cartão de gestante) a partir de definições jurídicas e morais de avaliação dos comportamentos das mulheres, e não com parâmetros da biomedicina. Percebidas na relação materna, essas "anomalias" podem levar até à interrupção da própria gravidez, das quais o dispositivo sanitário se faz o guardião.

Segundo as normas sociais veiculadas nos serviços de saúde, a relação com a criança deve começar desde a gestação e se configurar rapidamente como "projeto de criança”, que será monitorizado pelos profissionais de saúde:

Se adolescente engravidar é de risco [...] porque muitas vezes não têm apoio e termina abortando a criança.

Eu tenho uma adulta (na minha área) que esconde quando está grávida, toma remédio para abortar, não assume que está grávida, eu digo pra ela que ela está grávida, mas ela fica escondendo, na verdade ela nem vem. 
$\mathrm{Na}$ prática, a noção de risco pode assumir vários conteúdos. Abortos (provocados) anteriores reaparecem fantasmagoricamente como riscos para a atual gravidez e leva à sua vigilância, na construção do "projeto de criança". A frequência mensal das visitas, o registro da gravidez nas unidades básicas do PSF e no sistema nacional de monitoramento pré-natal (SIS-Pré-natal) e o cartão de identificação da gestante trabalham na diminuição dos abortos provocados. Paralelamente à existência de técnicas repressivas e proibitivas, como a interdição legal do aborto, observa-se então que técnicas mais "soft" ou ainda "técnicas do eu" - segundo a fórmula de Nikolas Rose (1989) - se desenvolvem e buscam modelar seres capacitados para agir sobre seus corpos e almas, a fim de obter os comportamentos adequados, sem ter que passar pela sanção violenta.

A noção de risco pode ir além da gravidez e uma "gravidez de alto risco" pode tornar-se uma "maternidade de risco", do ponto de vista relacional. O risco se localiza nas capacidades da mulher em cumprir seu papel materno. Segundo um médico entrevistado: "mulher doente não pode cumprir seu papel de mãe", em referência às mulheres portadoras do HIV. Não somente a mulher doente pode ser vista como incapaz, mas a própria figura materna pode transformar-se no principal fator de risco para a vida da criança. Uma enfermeira relatou:

Eu tive uma gestante que ganhou uma nenezinha, a menina nasceu desnutrida, baixo peso, mas ela tinha feito o pré-natal normal, não tinha tido nenhuma alteração durante o pré-natal [...]. Agora, eu percebia a barriguinha dela pequenininha, inclusive a encaminhei para o alto risco, mas o alto risco mandou-a de volta dizendo que estava bem [...]. Mas assim, eu achava ela um pouco desligadinha da criança [...] E ela não era adolescente, ela já tinha... acho que 29, 30 anos, por ai... E era uma bebezinha linda, coisa fofa [...]. E ela amamentava a criança, só que eu achava um pouco desligadinha [...] aí com aproximadamente 4 meses a criança foi a óbito. (Grifos nossos).

Este extrato de entrevista permite salientar vários pontos importantes. Em primeiro lugar, a clarificação necessária da enfermeira de que não se tratava de uma "mãe adolescente", deixando manifesto a estigmatização destas últimas. Em seguida, a questão dos riscos "não previstos", no pós-parto, ligados à "relação de risco" entre mãe e filho, que pode resultar na mortalidade infantil. O papel ativo das mães na morte da criança é uma ideia bastante difundida no Nordeste e até ligada a trabalhos acadêmicos. ${ }^{12}$ Por fim, entendem-se as vicissitudes do risco a partir da percepção de profissionais (DOUGLAS; WILDAVSKY, 2012), onde 
podem se confrontar avaliaçōes clínicas "objetivas" (no centro de referência de alto risco) com revelações do "risco relacional" para profissionais de proximidade.

\section{Gestão do risco e mudanças na regulação}

Quando o risco se refere a fatores biológicos e clínicos, as mulheres são encaminhadas para uma unidade de alto risco, onde o equipamento técnico é mais sofisticado e adaptado à consulta pré-natal. Para além dos processos de rotina, os procedimentos médicos como, por exemplo, seguir uma dieta especial ou um tratamento medicamentoso, são adicionados e individualizados de acordo com o "fator de risco" da gestação. Nesse sentido, as gestações que apresentam complicações continuam seguindo percursos clínicos ligados às particularidades de problemas específicos. O registro da medicalização estabelece uma primeira classificação e constrói trajetórias diversas nas experiências de gravidez, traduzindo-se em mais ou menos testes, controles, análises, medicamentos, etc.

No entanto, uma segunda classificação reside na utilização da categoria "risco" na gestão de gravidezes. Ela aparece como categoria "objetivante", para casos de gravidez assignadas como sendo fora das "normas procriativas" (BAJOS; FERRAND, 2002), como adolescentes, mulheres que abortaram ou poderiam abortar e outras "desligadinhas". Para essas gestaçôes, as técnicas da regulação se concentram sobre um registro sanitarizado.

Segundo o Ministério da Saúde, as consultas para gestação de alto risco ${ }^{13}$ devem se dar mais frequentemente, e elas supōem sempre "uma entrevista", o que denota mudanças nas práticas dos profissionais de saúde que passam a diagnosticar e também tratar a partir da "palavra" (MEMMI, 2000). Dentro das instituições biomédicas, surge um deslocamento da visão da gravidez de fenômeno físico-anatômico, onde o médico representava o saber (configuração ligada à medicalização e que foi alvo de fortes críticas, no âmbito da saúde materno-infantil) para situação de transformação, onde a mulher tem sua psique perturbada e será então submetida a outros tipos de intervenção.

Essa superposição dos registros medicalizado e sanitarizado da gravidez e do parto cria bases para uma reconfiguração do próprio sistema de saúde, que deverá incluir novas disciplinas no atendimento, modificando as instâncias, regras e técnicas da regulação dos comportamentos das mulheres grávidas. Um médico em uma maternidade diz: 
Adolescente é assim: aqui em princípio elas não são consideradas de alto risco, mas elas são atores específicos [...]. Então, elas têm que ter uma avaliação mais cuidadosa, e também pela questão social. Você às vezes tem que formar um grupo multidisciplinar, ver o que elas comem...Então elas têm um trabalho específico [...] porque elas trabalham com os psicólogos, então eles consideram até adolescente um pouco mais velho, né? Então, às vezes, em relação à idade, eles consideram assim para marcar: de 12 até $18 . .$. Elas têm um apoio melhor, né? A doutora que faz as consultas no ambulatório, ela está muito atenta [...] para detectar algum tipo de ansiedade. As meninas vêm às vezes com uma rejeição grande em relação à gravidez, geralmente vêm duma briga com o namorado, né? Então, não é assim pra todas as gestantes, vêm da triagem aquelas que estão precisando, como aquelas que têm AIDS, e daí elas encaminham.

$\mathrm{Na}$ prática médica, aparece então a discriminação entre dois grupos: a "gravidez (fisiologicamente) de risco" e a "maternidade (socialmente) de risco" que precisa de apoio "pela palavra". No bairro, elas serão mais controladas pelos serviços locais enquanto no hospital, serão encaminhadas sistematicamente para $\mathrm{o}$ atendimento psicológico.

É interessante notar que as discussões com as mulheres tornam-se um instrumento de regulação fundamental dentro do dispositivo sanitário, durante as consultas e tal qual o Ministério da Saúde recomenda. Dominique Memmi (2003) chama isto de "governo pela palavra", situação em que a "escuta" torna-se o dispositivo que procura que a mulher produza um discurso legítimo sobre a relação com seu corpo, a gravidez e a futura criança. As "discussões entre mulheres", como o grupo de gestantes nos postos de saúde, tornam-se epicentro para a transmissão de normas.

\section{Limites da "palavra"}

Deve-se notar, contudo, que o dispositivo não é totalmente operacional na sua atuação. Por um lado, a introdução de novas práticas, de "verbalização" e de "escuta", produz novas lutas e confrontos corporativistas entre profissionais de saúde, mostrando que alguns domínios profissionais ainda se opõem à passagem a outro modelo biomédico. Assim, a circunspecção com a "palavra", por parte de alguns profissionais, é notável nas observaçōes, durante as consultas do pré-natal, sejam elas na unidade de saúde ou nas maternidades. Muitas vezes, o dispositivo de "escuta" é invertido e o profissional discorre largamente ao contar sua própria vida como modelo comportamental. Os padrōes hierárquicos das interaçôes médico-paciente são restabelecidos. 
Os pacientes, entretanto, também relutam em exprimir seus sentimentos, pelo menos em um discurso "inteligível" para o profissional. Como Memmi observa na França, aos olhos dos profissionais, o modelo em que as mulheres seriam as "guardiãs dos seus próprios corpos" está longe de ser uma realidade, porque existem falhas nos diálogos, assim como a não adesão aos padrões. Para algumas mulheres de camadas populares, não é fácil fazer uma restituição racionalizada do "si corporal" (MEMMI, 2004, p. 143), como as mulheres das camadas médias o fazem. Os profissionais de saúde recebem aqueles "sim-não irritantes" que não lhes permitem "avançar na discussão com elas". Uma médica lamenta:

Não sabem às vezes escrever e tal, então fica difícil você explicar pra elas como é que ela vai usar o remédio, de quantas em quantas horas, essas coisas, então você tem que utilizar outra linguagem para aquelas pacientes, para não haver assim [...] um choque muito grande com o entendimento, sabe? Porque às vezes elas não entendem o que você está perguntando, elas não perguntam[...] É difícil conversar com elas.

Com relação aos riscos ligados à gravidez, essas falhas na comunicação traduzem menos uma não percepção do risco - como os profissionais acham e como se o risco fosse objetivamente determinado - do que lógicas distintas, na construção social do risco gestacional, que os profissionais de saúde tendem a ver como uma ignorância por parte das mulheres.

Se, como foi observado, essa flexibilidade do enfoque do risco permite uma intervenção que se adapta às prerrogativas e visóes institucionais, para um controle mais assíduo, essa plasticidade é encontrada também nas mulheres. A assignação ao risco - e à maternidade de risco - não é completamente disciplinária e de um poder "imperativo". Ela se constrói num espaço que deixa margens ao modo "condicional" da experiência.

\section{A subjetivação do risco na experiência das mulheres: do sanitário-individual ao coletivo-relacional.}

Para as mulheres, a experiência da gravidez que se realiza a partir da categoria de risco está associada a um aumento de responsabilidades, vivido tanto subjetiva como objetivamente. Segundo Priscila, uma jovem mãe de 17 anos:

Mesmo se não era de risco, ser mãe de risco foi para mim uma experiência muito boa porque aí tive mais responsabilidades. Me tornei mais responsável por mim e pela minha filha. [...] Lá, nos serviços de alto risco, nos fazem 
compreender, às mães de alto risco, que temos mais trabalho para fazer para proteger a criança. (Grifos nossos).

Assim, ser mãe de "alto risco" funcionaria como um excedente do papel materno delegado aos cuidados diversos, tarefas e atenção com a criança (care), apelando a um acréscimo da responsabilidade individual para com a saúde e a vida do feto. Procura-se criar uma "biopolítica delegada" (MEMMI, 2004) aos indivíduos na gestão dos perigos associados à própria saúde e a do feto. $\mathrm{O}$ risco transcende o próprio campo da saúde para criar normativas - sanitarizadas - no seio da família e mais especificamente no laço filial mãe-filho.

No entanto, se as técnicas do dispositivo, tal como a procura da expressão pela "palavra", não são completamente operacionais; os efeitos procurados também não são realizados. Se se procura responsabilizar as mulheres, através da construção de uma percepção pessoal, íntima e psicológica que esteja, ao mesmo tempo, em acordo com os padrões sanitários, há diversos contrastes com a construção do risco nas mulheres. Por exemplo, a incompatibilidade entre a atribuição institucional do risco e a percepção do risco nas mulheres - como Priscila formula pelo "mesmo não sendo de risco (clinicamente), ser mãe de risco (considerada assim)" - não pelas dificuldades para elas de perceber o risco, mas pela percepção da arbitrariedade na atribuição. Isto é especialmente notável entre adolescentes ou em mulheres que sentem a atribuição de "alto risco" como um constrangimento. Para Flávia, que apresentava excesso de peso:

Todo o mundo me dizia que não aparentava, que minha barriga era muita linda. É só a medicina que achava que meu peso excedia, é. (Grifos nossos).

Estar acima do peso não é percebido como um risco legítimo, sobretudo porque essa percepção é construída não individualmente, mas pela mediação de "todo o mundo", suas pessoas próximas, sua família. O risco aparece aqui como construído não só de maneira institucional ou individual, mas a partir das relações sociais significativas da pessoa. Observa-se que tanto a percepção do risco como a assignação de "mãe de risco" são reconstruídas pelas mulheres de camadas populares a partir de um afastamento identificatório. Se elas não são passivas, não é devido a uma construção individualizada que não suportaria a rotulação institucional, mas porque essa individualização se faz a partir da apropriação diversificada e coletiva do risco. 


\section{Os arranjos na experiência das mulheres}

Contudo, a relação entre as experiências das mulheres e a assignação do risco não é somente negativa. Muitas mulheres aderem à assignação institucional. Porém, a adesão não significa submissão e elas modulam, pela própria experiência social, o rótulo institucional do risco que se torna útil em certas situações. Ser "de risco" permite às mulheres um conhecimento mais depurado dos diversos serviços e precauções, no momento do nascimento, sobretudo para encontrar uma vaga em uma maternidade numa cidade na qual a falta de leitos para dar à luz constitui um problema sanitário muito grave. ${ }^{14}$ Elas demostram a capacidade de mobilizar o rótulo de risco. Como Laurie Denyer Willis (2009) observou em um bairro de São Paulo, às vezes as mulheres procuram voluntariamente ser reconhecidas como "de risco", para ter acesso a cesarianas que são limitadas pelas normativas relacionadas com o programa de humanização. As mulheres mobilizam o registro do risco para pedir mais cuidados, mais exames e mais tecnologia médica. Muitas delas expressam também desconfiança com relação ao atendimento prestado pelo sistema público durante o pré-natal, e utilizam o rótulo "alto risco" para ter acesso a serviços que lhe seriam negados, em outras situaçôes. Uma mulher com um quadro de hipertensão expõe:

Eu dizia "estou sentindo dor". Agora, eu não estava sentindo, era só para saber se eu estava bem mesmo ou se não estava. Para fazer mais um ultrassom, agora todo dia eu estava no hospital, para saber se eu estava bem ou se tinha alguma coisa errada comigo, para saber se faziam o trabalho certinho.

De maneira mais substancial, há uma discrepância entre o tratamento institucionalizado e individualizado do risco e uma experiência coletiva da gravidez nas mulheres. As técnicas do dispositivo tendem a responsabilizar a mulher através de categorias sanitarizadas cada vez mais individualizadas. Também ele visa à criação de uma percepção íntima e psicológica nas mulheres, que esteja, ao mesmo tempo, de acordo com os padróes sanitários. Mas essas técnicas nem sempre funcionam na prática. Este ponto é fundamental para relativizar a força de influência do dispositivo, nas experiências da maternidade em camadas populares de Recife.

Demostrou-se como a "dimensão relacional" se constrói nas regulações sanitarizadas, seja como "fator de risco" (relação conjugal insegura, famílias desestruturadas, etc.), seja como "relação de risco" (entre a mulher e a criança). 
Se no monitoramento das gravidezes a "prioridade [é] dada a um indivíduo solitário” (MEMMI, 2003, p. 29), cada vez mais a dimensão relacional tornase importante para o dispositivo da qual ele procura ser o depositário. No entanto, as visões desenvolvidas aparecem como rígidas e estereotipadas, quando comparadas à real dimensão relacional da experiência da gravidez de mulheres de camadas populares. Nelas a gravidez é antes tudo uma experiência relacional que se constrói na rede primária que é menos "instável” do que fluida. Quando uma psicóloga de maternidade se ofusca porque as gestantes não escolheram o nome do neném ("Se tiver uma mãe que tá sem nome para o bebê, você pode avançar que há algo de errado nessa relação...”), observa-se, por parte das mulheres, estratégias diversas na escolha do nome das crianças, estratégias ligadas à inclusão na rede de apoio e por isso dependente de sua configuração. Por exemplo, uma jovem mãe que, em nosso primeiro encontro, pensava deixar a mãe do parceiro escolher o nome da criança (reforçando assim a rede conjugal), quando a encontramos dois anos depois, finalmente, o nome da criança fora dado pela sua própria mãe, pois ela tinha se separado do namorado, o pai da criança. Outras mulheres, por exemplo, escolhem vizinhos, amigos e parentes para darem os nomes aos filhos e assim reforçar laços.

Também, e em especial entre as mulheres que vivem uma gravidez "de risco", na qual há mais responsabilidades para assumir, recorre-se com maior força à rede de apoio, operando uma "coletivização" da gravidez de risco. As mulheres grávidas mudam frequentemente de sua casa para a de uma mulher próxima à família. É comum também uma vizinha, irmã ou amiga, que se muda durante um tempo para a casa da mulher grávida, para "tomar conta da casa”, enquanto a mulher está impossibilitada. São essas mulheres da rede primária que dão orientação sobre nutrição e cuidados durante a gravidez. Elas cuidam dos outros filhos ou emprestam dinheiro para ter acesso aos serviços privados ou aos exames mais caros.

Mariceia, 48 anos, cria dois dos netos. Um deles, João, mora com ela desde seus dois meses, pois os pais dele são portadores de HIV. Ela diz que a nora tem "feito tudo o que tinha que fazer": "o pré-natal de alto risco" - porque "foi considerada assim" - "ela teve uma cesariana" e "tomou o coquetel" (tratamento antirretroviral). O pequeno João "também tomou retroviral durante três meses. Agora ele não tem nada, ele tem uma saúde de ferro [...]. A mãe dele não tinha paciência, também, aí ela ficava nervosa quando ele chorava de madrugada e ficava agitado e ela tinha dor de cabeça. Aí, eu peguei ele quan- 
No caso, a categoria médica e sanitária de risco gestacional individual combinase não somente com um “complexo de perturbações físico-morais” (DUARTE, 2003) misturando "nervos" e "paciência", mas também com uma experiência em rede da maternidade. Dessa maneira, a noção epidemiológica do risco sofre modulações no contexto estudado, pois ela faz referência a doenças ou problemas que serão vivenciados por mulheres que constroem a experiência da maternidade a partir de suas relações. A medicalização, a sanitarização e a individualização da gravidez, que se operam através da categoria "risco", encontram diferentes matizes em pessoas que dão sentido a suas experiências a partir da trama de relações nas quais elas estão inseridas.

\section{Considerações finais}

As consultas do pré-natal atuam como instrumento de regulação para uma maior responsabilização, individualização e racionalização (DUARTE, 1992) da experiência da gravidez a partir da noção de risco. Salienta-se o fato de que ela não necessariamente está conjugada a um excedente de medicalização, mas que produz outros tipos de classificações que levam a uma sanitarização da experiência. Com efeito, ela está associada a um conjunto de técnicas de regulação que acentuam a procura do bem-estar, da fala livre, da autonomia e da personalização da gravidez. As precauções ligadas ao risco, o "acompanhamento", a "escuta”, a construção de um "projeto", como modalidades de cuidados, tornam-se as intervenções essenciais na saúde pública e as novas técnicas de regulação do dispositivo. Observou-se como a noção de risco é polissêmica e serve para a implementação de regulações que vão tanto no sentido de uma medicalização como de uma sanitarização, mas também de que maneira essa polissemia pode ser mobilizada pelas mulheres, na demanda tanto de mais procedimentos médicos como de um tratamento humanizado.

Se o dispositivo de saúde produz regulaçóes que pretendem criar um projeto individual e sanitarizado de criança nas mulheres grávidas de camadas populares, como solução econômica da mortalidade materno-infantil (ao mesmo tempo em que se evitam abortos clandestinos), esses projetos são considerados pelas mulheres dentro da esfera doméstica e da rede de apoio. 
Os profissionais de saúde alarmam-se com o fato de esse projeto não ser construído na "racionalidade" do planejamento e ser feito por mulheres que não estão "preparadas" (psíquica e fisicamente). Contrariamente, na prática das mulheres, ele se constrói sobretudo como um projeto (e responsabilidade) relacional, não necessariamente parental ou conjugal, mas nas redes de apoio que vão além da família nuclear, mostrando outras formas de lidar com os riscos gestacionais, longe do quadro individualizado da gestante atomizada que autorregula racionalmente os "cuidados de si".

As novas regulações que levariam a uma individualização na gestão do próprio corpo e a uma "biopolítica delegada" (MEMMI, 2004) devem ser reavaliadas a partir das modulações e reinterpretaçōes que sofrem nas experiências das mulheres, tal como foi observado. Mas também deve ser reavaliada a própria noção de individualização e as limitaçôes de uma perspectiva unilateral dessa noção, para repensar a possibilidade de existência de uma heterogeneidade nos processos de individualização. As mulheres brasileiras de camadas populares constroem suas experiências "individuais" inseridas numa trama de relações, ativas nas tomadas de decisões, que cuidou dela e do neném e que participou material e simbolicamente da gravidez. Convém então viabilizar novas análises dos processos de individualização no âmbito da saúde no Brasil popular que permitam pensar singularidades de certos processos reprodutivos que se dão justamente no emaranhado de relações e que se vêm confrontados a modelos etnocêntricos de cuidados acunhados a partir de noções como a de risco.

\section{Referências}

BAJOS, N.; FERRAND, M. De la conception à l'avortement: sociologie des grossesses non prévues. Paris: Inserm, 2002. 348 p.

BERLIVET, L. Déchiffrer la maladie. In: DOZON, J.P.; FASSIN, D. Critique de la santé publique. Une approche anthropologique. Paris: Ballan, 2001. p. 75-102.

BOLTANSKI, L. La condition foetale. Une sociologie de l'engendrement et de l'avortement. Paris: Gallimard, 2004. 420 p.

BRANDÃO E. Gravidez na adolescência: um balanço bibliográfico. In: HEILBORN, M.L. et al. (Org.). O aprendizado da sexualidade. Reprodução e trajetórias sociais de jovens brasileiros. Rio de Janeiro: Garamond, 2006. p. 63-96.

BRASIL. Ministério da Saúde. Pesquisa nacional de demografia e saúde da criança e da mulher. Brasília: PNDS, 1996 e 2006. 

Ministério da Saúde. Secretaria de Atenção à Saúde. Departamento de Ações Programáticas Estratégicas Gestação de alto risco: manual técnico. Brasília: Ministério da Saúde. 2010. 304 p.

- Ministério da Saúde. Secretaria de Gestão do Trabalho e da Educação na Saúde. Universidade Aberta do Sistema Único de Saúde. Competências dos profissionais de nível superior na estratégia de saúde da família. Brasília: UNA-SUS, 2011. 90 p.

BUCHABQUI, J. A.; CAPP E.; FERREIRA J. Adequação dos encaminhamentos de gestações de alto risco na Rede Básica de Atenção à Saúde de Porto Alegre, Rio Grande do Sul, Brasil. Revista Brasileira de Saúde Materna-Infantil. Recife, v. 1, n 6, p. 23-29, 2006.

BUTLER, J. Le pouvoir des mots. Discours de haine et politique du performatif. Paris: Amsterdam, 2004. 287 p.

CALVEZ, M. Le risque comme ressource culturelle dans la prévention du sida. In: DOZON, J.P.; FASSIN, D. Critique de la santé publique. Une approche anthropologique. Paris: Ballan, 2001. p. 127-143.

CAMARGO JUNIOR, K.R. Medicalização, farmacologização e imperialismo sanitário. Cadernos de saúde pública. Rio de Janeiro, v. 29, n. 5,p. 844-846, 2013.

CANDEIAS, N.M.F. Educação em saúde na prevenção do risco gravídico pré-natal e interconceptional: algumas características do comparecimento a serviços de assistência prénatal. Revista de Saúde Pública. São Paulo, n. 14, p. 820-832, 1980.

CASTEL, R. La gestion des risques. De l'anti-psyquiatrie à l'après-psychanalyse. Paris: Minuit, 2011. 222 p.

CASTIEL, L.D. Vivendo entre exposições e agravos: a teoria da relatividade do risco. Revista História, Ciências, Saúde - Manguinhos. Rio de Janeiro, v. 3, n. 2, p. 237-264, 1996. CLARKE, A. et al. Technosciences et nouvelle biomédicalisation: racines occidentales, rhizomes mondiaux. Sciences sociales et santé. Paris, v. 18, n. 2, p. 11-42, 2000.

CONRAD P., The medicalization of society: On the transformation of human condition into treatable disorders. Baltimore: The Johns Hopkins University Press, 2007. 224 p.

CORREA, M.; GUILAM, M.C. O discurso do risco e o aconselhamento genético prénatal. Cadernos de Saúde Pública. São Paulo, v. 22, n. 10, p. 2141-2149. 2006.

COSTA-MARTINS, T.; HEILBORN, M.L. Gravidez na adolescência e fatores de risco entre filhos de mulheres nas faixas etárias de 10 a 14 e 15 a 19 anos em Juiz de Fora, MG. Revista APS, v. 9, n. 1, p. 29-38, 2006.

DENYER, L. M. Call me 'at-risk': maternal health in Sao Paulo's public health clinics and the desire for cesarean technology. Massachusetts. Tese (Doutorado) - Massachusetts Institute of Technology, 2009.

DOZON, J-P.; FASSIN, D. (Orgs.). Critique de la santé publique. Une approche anthropologique. Paris: Balland, 2001. 361 p . 
DOUGLAS, M.; WILDAVSKY, A. Risco e cultura. Um ensaio da seleção de riscos tecnológicos e ambientais. São Paulo: Campus, 2012. 224 p.

DUARTE, L.F.D. et al. Vicissitudes e limites da conversão à cidadania nas classes populares. Rio de Janeiro, 1992 (mimeo).

DUARTE, L.F.D. Indivíduo e pessoa na experiência da saúde e da doença. Revista Ciência \& Saúde Coletiva. São Paulo, v. 1, n. 8, p. 173-183, 2003.

DUARTE, L.F.D.; CAMPOS GOMES, E. Três famílias: identidades e trajetórias transgeracionais nas classes populares. Rio de Janeiro: Fundação Getulio Vargas, 2008. 316 p.

FAYA ROBLES, A. L'humanisation de l'accouchement et de la naissance au Brésil: de nouveaux dispositifs de régulation des corps des femmes pauvres? Revue Lien social et Politiques, n. 59, p. 115-124, 2008.

. Las agentes comunitarias de salud en el Brasil contemporáneo: la "policía amiga" de las madres pobres. Revista Sexualidad, Salud y Sociedad, n. 12, dic. 2012. Disponível em: <http://www.e-publicacoes.uerj.br/index.php/SexualidadSaludySociedad/article/ view/3718> Acesso em: 20 out. 2014.

FONSECA, C. Concepções de família e práticas de intervenção: uma contribuição antropológica. Revista Saúde e sociedade. São Paulo, v. 14, n. 2, p. 50-59, 2005.

. Os caminhos da adoção. São Paulo: Cortez, 1995. 152 p.

HEILBORN, M.L. Experiência da sexualidade, reprodução e trajetórias juvenis. In: HEILBORN, M.L. et al. (Orgs.). O aprendizado da sexualidade. Reprodução e trajetórias sociais de jovens brasileiros. Rio de Janeiro: Garamond, 2006. p. 30-58.

HISLOP, J.; ARBER, S. Understanding women's sleep management: beyond medicalizationhealthicization? Sociology of Health \& Illness. Oxford, n. 7, v. 25, p. 815-837, 2003.

KATZ, R. A. Adolescentes e maternidade: um destino, um problema, uma escolha? 1999. 149

p. Dissertação (Mestrado em Saúde da Criança) - Instituto Fernandes Figueira, Fundação Oswaldo Cruz. Rio de Janeiro. 1999.

KNAUTH, D.R. Idade e ciclo de vida. In: SOUZA-LIMA, A.C (Org.) Antropologia \& Direito. Temas antropológicos para estudos jurídicos. Rio de Janeiro: Contra Capa, 2012. p. 546-551.

MAGNANI, C.J.G. De perto e de dentro: notas para uma etnografia urbana. Revista Brasileira de Ciências sociais. São Paulo, v. 17, n. 49, p. 11-29, 2002.

MEMMI, D. Administrer une matière sensible. Conduites raisonnables et pédagogie par corps autour de la naissance et de la mort. In: FASSIN, D.; MEMMI, D. (Orgs.). Le Gouvernement des corps, Paris: EHESS, 2004. p. 135-154.

Faire vivre et laisser mourir. Le gouvernement contemporain de la naissance et de la mort. Paris: La Découverte, 2003. 

. Vers une confession laïque? La nouvelle administration étatique des corps. Revue Française de Science Politique. Paris, v. 50, n. 1, p. 3-19, 2000.

NEVES, E.M. Antropologia e ciência: uma etnografia do fazer científico na era do risco. São Luís: EDUFMA, 2008.

ROSE, N. Governing the soul: the shaping of the private self. London: Routledge, 1989.

TORNQUIST, C. S. Parto e poder: análise do movimento pela humanização do parto no Brasil, Tese (Doutorado) - Universidade Federal de Santa Catarina, Florianópolis, 2004.

SANABRIA, E. From sub- to super-citizenship: sex hormones and the body politic in Brazil. Ethnos, Journal of Anthropology, v. 75, n.4, p. 377-401, 2010.

SARTI, C.A. A família como espelho. Um estudo sobre a moral dos pobres. Campinas: Autores Associados, 1996, 128 p.

SCOTT, R.P. Gênero, família e comunidades: observações e aportes teóricos sobre o Programa Saúde da Família. In: VILLELA, W.; MONTEIRO, S., (Orgs.). Gênero e Saúde. Programa Saúde da Família em questão. Rio de Janeiro: Abrasco, 2005. p. 75-100. Risco, reprodução e gênero na mortalidade infantil. In: ENCONTRO ANUAL DE ANPOCS, 31., Caxambu-MG. Anais... 22-26 out. 2007, Caxambu-MG, 2007.

SILVEIRA, D.M.I. Gestação de alto risco. Manual Técnico. 3. ed Brasília: Ministério da Saúde. 2000. 304 p.

STERN, C.; GARCIA, E. Hacia un nuevo enfoque en el campo del embarazo adolescente. Reflexiones, sexualidad, salud y reproducción. México: Programa Salud Reproductiva y Sociedad, 1999.

VÍCTORA, C.G. et al. Saúde de mães e crianças no Brasil: progressos e desafios. The Lancet. Series 11, 2011, p. 32-46. Disponível em: http://download.thelancet.com/flatcontentassets/ pdfs/brazil/brazilpor2.pdf. Acesso em: 1 out. 2014.

WEBER, F. Le sang, le nom et le quotidien. Une sociologie de la parenté pratique. La Courneuve: Aux Lieux D'être, 2005. 264 p.

WOORTMANN, K. A família das mulheres. Rio de Janeiro: Tempo Brasileiro, 1987. 316 p. ZORZANELLI R.T.; ORTEGA F.; BEZERRA J.B. Um panorama sobre as variações em torno do conceito de medicalização entre 1950 -2010. Ciência \& Saúde Coletiva. Rio de Janeiro, v. 19, n. 6, p. 59-67, 2014.

\section{Notas}

${ }^{1}$ O neologismo "assignação" aparece primeiramente como sinônimo de "atribuição". Mas a atribuição do risco por parte das instituiçôes sanitárias e a passagem de uma "gravidez" para uma "gravidez de risco" implica uma "interpelação" do poder, no sentido de Althusser, na qual o sujeito responde ao chamado e fazendo-o torna-se sujeito. Esse mecanismo é ilustrado pela imagem de um policial 
chamando: “psiu, ei você!” à qual o sujeito atende voltando-se para trás. A perspectiva althusseriana do indivíduo construindo-se como sujeito a partir de uma interpelação do poder é aprofundada por Judith Butler, que a liga à construção de gênero: "Ao receber um nome, nós somos, por assim dizer, localizados socialmente no tempo e espaço" (BUTLER, 2004, p. 51). A noção de "assignação" é então utilizada no sentido da "interpelação", tal como utilizado por Butler, como ato discursivo, mas conjugado com aquele de "designação" que delimita um lugar social a ser ocupado. Assignação é então o mesmo processo corporal e enunciativo pelo qual há "convite" para ocupar uma determinada função e posição, no caso uma "assignação à maternidade".

${ }^{2}$ É importante notar que o artigo centra-se nas experiências de mulheres que não apresentavam riscos graves biomédicos e que são alvo fundamentalmente de regulações sanitarizadas. Não podemos inferir, entretanto, que o modo de regulação das mulheres presentando riscos biomédicos seja inteiramente medicalizada. Essas mulheres também podem ser alvo de uma regulação sanitarizada e cujas intervenções mobilizam valores e práticas relativas à relação de filiação, abrindo possibilidades de futuras pesquisas nesse sentido.

${ }^{3}$ A pesquisa de doutorado foi defendida na Université de Toulouse em julho 2011, sob a direção de Angelina Peralva. A pesquisa coletiva, na qual a pesquisadora participou, foi realizada sob a coordenação de Parry Scott e tratava da mortalidade infantil em camadas populares no Recife, Núcleo FAGES/ UFPE, 2006-2008.

${ }^{4}$ A pesquisa foi aprovada pelo Comitê de Ética em pesquisa do CISAM/Recife (n. de protocolo: CEP/ CICAM 003-06). Conforme a Resolução no 196/96 do CNS e atendendo às exigências do Comitê de Ética, foi apresentado para todos os participantes da pesquisa um Termo de Consentimento Livre e Esclarecido, explicando os objetivos gerais da investigação e garantindo o sigilo dos dados coletados e anonimato dos informantes. Todos os nomes próprios são fictícios.

${ }^{5}$ Fonte: SINASC (Sistema de Informaçôes sobre os Nascidos Vivos), Ministério da Saúde, MS/ SVS/DASIS.

6 "Rather than focusing on specific disease aetiologies, helthicization claims to recognize the role of multiple causal agents, embedded withi the social context of peaples' lives, as responsible for creating the potential for imbalances in health and wellbeing" (HISLOP; ARBER, 2003, p. 817).

${ }^{7}$ É relevante o fato de que a noção de "risco" na saúde aparece vinculada principalmente à saúde materno-infantil. Em outras áreas ele aparece mais tarde; por exemplo, para os "riscos sanitários" nos quais vemos maior quantidade de artigos a partir dos anos 1990. Da mesma maneira, procurando artigos em bases como Lilacs e Scielo, foi encontrado um artigo só, em 2002, articulando risco e paternidade, a partir de pesquisa em psiquiatria sobre alcoolismo em pais e adoecimento psíquico nas crianças.

${ }^{8}$ É interessante notar a evolução desses fatores no manual publicado mais recentemente, em 2011, pois alguns dos pontos críticos desenvolvidos aqui decorrem da utilização pelas equipes do manual de 2000 .

${ }^{9}$ Cabe lembrar também o fato de que, para o Estatuto da Criança e do Adolescente, Lei n.o 8069/90, adolescente é todo indivíduo com idade entre 12 e 18 anos. A primeira indicação brasileira para a classificação derivava diretamente da definição da OMS, que considera a gravidez na adolescência em mulheres menores de 19 anos como sendo "gestaçôes de alto risco". Num primeiro momento, o mesmo parâmetro é adotado pelo Ministério da Saúde, produzindo uma junção entre a maioridade legal e o risco gestacional. O corte de idade para 19 anos mudou para 15 anos na quinta e última versão do Manual técnico para gestaçôes de alto risco, do Ministério da Saúde. Nessa versão, é agregado outro parâmetro: o da menarca há menos de dois anos. 
${ }^{10} \mathrm{Na}$ versão de 2010 do Manual técnico para as gestações de alto risco, foram incluídos outros itens, como as anormalidades estruturais nos órgãos reprodutivos (sem especificar quais seriam essas anormalidades) e os "hábitos de vida", especificando ao lado "fumo-álcool".

${ }^{11}$ Fonte: Dados do SIM/SINASC/DINAM/DVS/Secretaria de Saúde de Recife para a pesquisa "Mortalidade neonatal infantil: representaçōes e riscos para adolescentes e adultos no Recife", trabalhados por Sílvia Sarinho e Parry Scott

${ }^{12}$ Sobre a mortalidade infantil no Nordeste brasileiro, ver o trabalho de Scheper-Hughes (1985, 1997). Para uma crítica deste trabalho, consultar: Nations e Rebhun (1988), Nations (2008) e Franch e Lago-Falção (2004).

13 "Nas gestações de alto risco, o intervalo das consultas deve ser menor, e ajustado regularmente de acordo com a as necessidades individuais de cada usuária. Em cada consulta são realizadas a entrevista e o exame físico [...]” (BRASIL, 2000).

${ }^{14} \mathrm{~A}$ falta de leitos e as peregrinaçóes das mulheres para dar à luz foram apontadas desde 2010 como constituindo também um "fator de risco". Assim, novos programas de saúde pública (Mãe Coruja, Mãe Cegonha, etc.) contemplam essa atribuição da vaga numa maternidade para as gravidezes de alto e baixo risco. 


\section{Abstract}

From the "risk pregnancy" to the "risk maternity". Biopolitic and health regulation in working class women experience in Recife, Brazil

The epidemiological risk category currently organizes, in Brazil, the management of pregnancies in order to achieve health goals, such as reducing infant and maternal mortality. This category is framed in an entire transformation in the health system, the transition to a new biomedical step based on the assessment and risk monitoring. Few studies in the social sciences took risk as empirical object of study from a perspective of critical analysis of the changes he introduced in social practices. Based on a broader research work with ethnographic methodology, the paper proposes to examine this category in the management of pregnancies in public health services and lower classes of women in the city of Recife, Brazil. The article will examine the modalities of regulation, increasingly individualized and sanitized, linked to the use of the notion of risk by health professionals and stigmatizing social representations for women of lower classes. Finally, the article relativizes the disciplining force of this biomedical category to show how it is subjectivized by women in a relational experience of pregnancy.

> Key words: risk; pregnancy; regulation; medicalization; healthicization. 